\title{
无机化学及无机化学实验中的思政元素
}

\author{
张玉荣*，袁耀锋 \\ 福州大学化学学院, 福州 350108
}

摘要: 无机化学及无机化学实验是化学专业学生最先接触到的专业基础课。本文梳理了这两门课程中专业知识与思 政元素的结合点, 并着重从培养学生的思辨精神和科学发展观、社会责任感和担当及 “爱国、敬业、诚信、友善” 的价值观这三方面来说明课程思政在育人中的重要性。

关键词: 无机化学; 无机化学实验; 课程思政

中图分类号: G64; O6

\section{Elements of Ideology and Politics Education in the Courses of Inorganic Chemistry and Inorganic Chemistry Laboratory}

\author{
Yurong Zhang *, Yaofeng Yuan \\ College of Chemistry, Fuzhou University, Fuzhou 350108, China.
}

\begin{abstract}
Inorganic chemistry and inorganic chemistry laboratory are the first professional basic courses for students majored in chemistry. This article combs the joint points between the professional knowledge and ideological and political education, and illustrates the importance of course ideology and politics in educating students in terms of cultivating the students' characters of speculative spirit and scientific development concept, social responsibility and responsibility, and the values of "patriotism, dedication, integrity, friendliness".
\end{abstract}

Key Words: Inorganic chemistry; Inorganic chemistry laboratory; Course ideology and politics

为了贯彻习近平总书记在全国高校思想政治工作会议上的重要讲话精神, 各个高校都在积极开 展 “课程思政” 的建设。其目的就是发挥课程的育人功能, 发挥广大教师在课程教学中的育人作用, 实现 “立德树人” 这一中心目标。“课程思政” 不同于纯粹的思政课程, 是通过挖掘专业课程中的思 政元素, 将专业知识与育人有机地结合, 达到 “润物细无声” 的育人效果, 形成专业课程与思政课 程同心同向的育人格局。

无机化学及无机化学实验是化学专业学生最先接触到的专业基础课。无机化学的主要内容是物 质结构基础、化学原理和元素及其化合物的性质。无机化学实验主要涉及无机化合物的合成与提纯 实验、化学原理实验、常数测定实验及元素化合物的性质实验。这两门课都有丰富的思政内容，对 于价值观及人生观尚在发展的大一新生来说, 如果上课时善加引导, 对培养学生的思辨精神、家国 情怀及诚实守信等优秀品质大有裨益。许多老师结合自己的教学实践, 对思政教育在无机化学及无

收稿: 2020-07-18; 录用: 2020-08-18; 网络发表: 2020-09-02

“通讯作者, Email: rongwei@fzu.edu.cn

基金资助: 福建省教育厅 2019 年省级线下一流本科课程项目; 福州大学一流本科教学改革建设项目; 福州大学化学一流本科教学重点核心课 程建设项目；福州大学第一批思政类 “金课”建设项目 
机化学实验教学过程中的应用进行了很好的总结, 为这些课程的思政建设提供了丰富的样例 ${ }^{[1-8]}$ 。本 文梳理了无机化学及无机化学实验的教学内容与思政元素的融合点(表 1), 并着重从培养思辨精神和 科学发展观、社会责任感和担当及正确价值观这几方面来说明课程的育人功能。

表 1 无机化学及无机化学实验中的思政元素融合点

\begin{tabular}{|c|c|c|}
\hline 章节 & 内容 & 思政元素融合点 \\
\hline 化学热力学基础 & 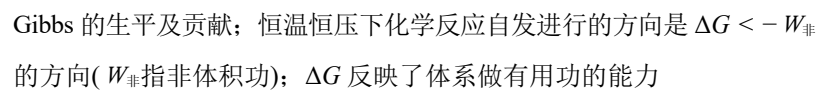 & $\begin{array}{l}\text { 不计名利、执着探究的精神; } \\
\text { 不怨天无人, 自省, 自强 }\end{array}$ \\
\hline 化学反应速率 & $\begin{array}{l}\text { 反应物分子的最低能量要求(能垒); 浓度、温度、催化剂等对自发反应 } \\
\text { 速率的影响; 定速步骤 }\end{array}$ & $\begin{array}{l}\text { 树立底线意识, 自律; } \\
\text { 合作和互助精神, 友善, 自省 }\end{array}$ \\
\hline 化学平衡 & 化学平衡是一种动态平衡, 条件变化平衡发生移动 & 生态平衡, 和谐社会, 社会责任感 \\
\hline 酸碱解离平衡 & $\begin{array}{l}\text { 酸碱理论的发展; 酸碱质子理论与共轨酸碱对; 缓冲溶液的性质与缓冲 } \\
\text { 容量 }\end{array}$ & $\begin{array}{l}\text { 科学发展观, 人类命运共同体; } \\
\text { 社会责任感与抗压教育 }\end{array}$ \\
\hline 氧化还原反应 & 电的发现及法拉弟的生平; 金属的腐蚀与防止 & $\begin{array}{l}\text { 执着的探究精神, 底线意识与奉献精 } \\
\text { 神 }\end{array}$ \\
\hline 物质结构基础 & $\begin{array}{l}\text { 原子结构的认识过程; 微观粒子的运动特征; 元素性质的周期性变化规 } \\
\text { 律; 共价键理论的发展; 离子极化理论; 分子间力; 不同类型晶体格点 } \\
\text { 间作用力差异对晶体性质的影响 }\end{array}$ & $\begin{array}{l}\text { 创新思维, 量变到质变, } \\
\text { 民族富强与凝聚力 }\end{array}$ \\
\hline 配位化学基础 & $\begin{array}{l}\text { 配位化学的发展史: Werner 与 Jørgensen 对化学式为 } \mathrm{Co}\left(\mathrm{NH}_{3}\right)_{6} \mathrm{Cl}_{3} \text { 的结 } \\
\text { 构的争论及 Werner 学说的确立; 配合物稳定性的定性判断; 配合物化 } \\
\text { 学键理论的发展; 配合物的手性、手性与药物的生理功能、手性催化剂 } \\
\text { 与手性药物的合成; 平面六边形配合物的合成; 利用 EAN 规则推测复 } \\
\text { 杂有机金属配合物的结构 }\end{array}$ & $\begin{array}{l}\text { 创新思维与思辨精神, 科学的发展 } \\
\text { 观, 社会责任感, 专业伦理, 科学前 } \\
\text { 沿与探究精神 }\end{array}$ \\
\hline$d s$ 区元素 & $\begin{array}{l}\text { 镉中毒与 “痛痛病” ; 录中毒与 “水俣病” ; 银纳米立方块与表面增强 } \\
\text { 多重光学防伪 }\end{array}$ & $\begin{array}{l}\text { 社会责任感和环保意识; } \\
\text { 科学前沿与探究精神 }\end{array}$ \\
\hline 针系元素 & 徐光宪院士的事迹与稀土的分离提纯 & “爱国、敬业” 的价值观 \\
\hline 实验绪论、化学 & 实验规范与安全教育、解离平衡与缓冲溶液、氧化还原电化学及元素的 & 安全意识、环保观念与实事求是; \\
\hline 原理类及性质实验 & 性质实验 & 理论联系实际的学习方法 \\
\hline $\begin{array}{l}\text { 常数测定及无机化合 } \\
\text { 物的提纯、制备实验 }\end{array}$ & $\begin{array}{l}\text { 阿佛加德罗常数及摩尔气体常数的测定、氯化钠的提纯、胆矾精制五水 } \\
\text { 硫酸铜、转化法制备硝酸钾、硫酸亚铁铵的制备、三草酸根合铁(III)酸 } \\
\text { 钾的制备及配阴离子电荷的测定等实验 }\end{array}$ & $\begin{array}{l}\text { 诚信、友善及互助的价值观; } \\
\text { 深入分析问题的能力 }\end{array}$ \\
\hline
\end{tabular}

\section{1 思辨精神和科学发展观的培养}

科学就是在理论与实践的不断冲突中向前发展, 理论在这个过程中日臻完善。以配位化合物的 化学键理论发展为例, 当 Werner 的配位理论被接受后, 为了说明配合物的空间构型及磁性, Pauling 于 1930 年提出了配位化合物的杂化轨道理论和价键理论, 但这一理论无法解释配合物的激发态行 为, 如相同形成体与不同配体结合时会表现出不同的颜色; 另外在配位单元构型未知的情况下很难 正确地判断出形成体的杂化方式, 比如单纯根据价键理论来判断 $\left[\mathrm{PtCl}_{4}\right]^{2-}$ 的空间构型就容易出错; 此 外, 对非经典配合物的稳定性等也无法解释。因此, 在 1953 年成功解释了 $\left[\mathrm{Ti}\left(\mathrm{H}_{2} \mathrm{O}\right)_{6}\right]^{3+}$ 的颜色后, 被 忽视了 20 多年的晶体场理论受到关注并得到迅速发展。该理论很好地解释了配合物颜色、磁性及第 一过渡系列元素 $\left[\mathrm{M}\left(\mathrm{H}_{2} \mathrm{O}\right)_{6}\right]^{2+}$ 水合热的双峰曲线等, 但无法解释光谱化学序列, 对非经典配合物中形 
成体与配体间的成键情况仍无法解释。晶体场理论的不足正是由于其忽略了形成体与配体轨道间相 互作用的结果。因此后面发展起来的分子轨道理论, 将配位单元作为一个整体来考虑, 很好地解决 了上述理论的遗留问题。除了上述三种理论外, 还有角重叠理论及将晶体场理论与分子轨道理论相 结合的配位场理论等 ${ }^{[9,10]}$ 。根据教学大纲, 课堂上详细地讲解了价键理论及晶体场理论, 但也对其他 理论概要地进行说明, 让学生了解相关理论的发展脉络及优缺点, 引导一些学有余力的学生去自学 课堂外的知识, 培养学生的思辨能力和科学的发展观。

另外, 在课堂上举一些违反常理的例子也有益于培养学生的辩证思维。以配合物稳定性的定性 判断为例, 当配位原子及配位数相同时, 通常认为螯合物稳定性大于简单的配合物, 但由于环张力 过大导致 $[\mathrm{Ag}(\mathrm{en})]^{+}$的稳定性不及 $\left[\mathrm{Ag}\left(\mathrm{NH}_{3}\right)_{2}\right]^{+}$。再比如软硬酸碱理论中认为 $\mathrm{Pd}^{2+}$ 为软酸, 与软碱结合 更稳定, 但如果已有 $\pi$ 酸配体与其配位, 则会使其硬度提高, 再接受新的配体时或外部条件改变时, 最稳定的配位方式可能与常理推测的不符。这说明在用任何理论时都不可生搬硬套, 要根据实际情 况, 分析各种影响因素后才能做出正确判断。

\section{2 培养社会责任感和担当}

在很多人眼里, 化学总是与污染、危害等相关联。而每一次化学品危害事故的发生又强化了人 们的这一认知。作为化学专业的学生, 毕业后很多都将从事与化学领域相关的工作, 因此在课堂上 适时地引入专业伦理教育, 能潜移默化地培养学生的社会责任感和担当, 使他们在将来的工作中能 从有益于社会的角度去考虑问题。比如讲到配合物的手性时, 为了说明对映异构体的差别, 举了反 应停的例子。反应停是 20 世纪 50 年代一家德国制药公司生产的能改善妊娠期妇女晨吐的药物, 不 幸的是服药的孕妇生下了四肢畸形的贞儿。1959-1963 年间因反应停致畸的婴儿达 1.2 万多名。事后 研究表明药物中的 $(S)$-异构体是导致悲剧的元凶 ${ }^{[10,11]}$ 。由于不同手性的物质生理功能差异巨大, 因此 具有特定手性的药物合成就显得尤为重要。1968 年威廉·诺尔斯制造了第一个具有手性的铑催化剂, 从而使治疗帕金森症的特效药一一左旋多巴的价格直线下降, 极大地减轻了患者的经济负担。诺尔

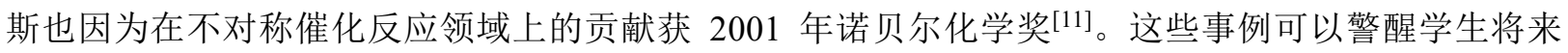
在进行药物、化学品等的推广时一定要慎之又慎, 要有严格的实验数据作依据, 这既是对生命的尊 重, 也是对社会负责, 同时又能激发学生利用专业知识造福人类的豪情。再比如讲到锌副族时, 我 们会讲到镉及求的危害。1912 年日本中部的神冈矿区附近的米农出现可怕的新疾病—— “痛痛病”, 1946 年当地的医生开始研究, 并于 1961 年锁定疾病的元凶为矿场的含镉废料污染所致 [11]。1956 年 日本熊本县水俣湾出现的怪病 “水俣病” 则是由于含大量录的工业废水排放污染造成的公害病。这 些臭名昭著的事件及实验课时强调实验废弃物的分类回收都可以用来教育学生尊重自然, 爱护青山 绿水, 树立可持续发展和环保意识, 培养社会责任感和担当精神。

此外, 在讲化学平衡时可将平衡的观念延伸到社会的和谐稳定及生态平衡上。如果一个人物欲 太强或染上恶习, 容易收支失衡, 陷入债务危机, 给自己和家人带来严重伤害, 甚至使一些人走上 犯罪的道路, 影响社会安定和谐。如果人们只会不停地向大自然索取, 如过度捕捞、过度排放、过 度砍伐, 必然导致环境恶化、生态失衡, 人类将自食恶果。正如共轭酸碱对相互依存一样, 人与人、 人与社会及人与自然也是相互依存的, 和谐社会、良好生态的创建需要所有人的共同努力, 每个人 都责无旁贷。

\section{3 培养 “爱国、敬业、诚信、友善” 的价值观}

最近时常有大学生在社交平台发表侮辱国家的言论被曝出, 让广大国民深为愤慨的同时, 也在 反思中国的教育究竟出了什么问题。尽管这些没有 “中国心” 的大学生只占很少的一部分, 但也说 明爱国主义教育不能只停留在思政课上, 还应有机地融入专业课的教学中。比如, 在物质结构部分, 物质的物理性质与微粒间的作用力是密切相关的, 正如民族凝聚力对国家富强的重要性, 这一类比 可以唤起学生心中对国家的使命感。讲到稀土元素时, 可以适时地引入徐光宪院士的生平事迹。徐 
院士 1951 年在美国哥伦比亚大学获博士学位后, 放弃国外优越条件, 毅然回国参与新中国建设, 因 为国家需要四次改变了研究方向, 从量子化学到配合物化学, 接着是核燃料萃取方向, 继而是稀土 分离。他在 20 世纪 70 年代建立了具有普适性的串级萃取理论并成功工业化, 改变了我国稀土资源 丰富但生产水平落后的状况, 使中国实现从稀土资源大国向高纯稀土生产大国的飞跃, 是实至名归 的 “中国稀土之父”。徐光宪院士也因为在稀土研究工作中的卓越贡献荣获 2008 年度 “国家最高科 学技术奖”。由于稀土资源的重要战略地位, 徐光宪院士在 2005 和 2006 年先后两次上书国家总理, 呼吁国家严控稀土开采量, 建立稀土储备制度 ${ }^{[12-14]}$ 。像徐光宪院士这样一心报国的科学家还有很多, 他们崇高的人格魅力在让学子们肃然起敬的同时, 也能激发学生的科研热情和家国情怀, 树立 “爱 国、敬业”的价值观。

除了 “爱国、敬业”, “诚信、友善” 也是我们社会和谐的基石。频频曝光的论文造假和抄袭事 件让我们看到诚信教育的重要性和必要性。在无机化学实验课的绪论部分, 我们对学生提出具体的 实验规范要求, 其中特别强调要如实记录实验数据和现象, 并在每次实验中反复强调。从笔者班上 的学生情况看, 学生确实做到了。记得在做 “胆矶精制五水硫酸铜” 的实验中, 有个学生在重结晶 时不小心把烧杯摔碎了, 结果没有产品, 实验报告中学生如实填写重结晶产量为 0 , 并对情况进行 了说明。类似的情形还有多起, 但学生都能照实记录, 让我颇感欣慰。当然, 学生这种诚实的行为 是与我们合理的过程评价机制分不开的。学生实验分数不仅仅取决于实验结果, 而是综合考虑学生 在整个实验过程中的表现, 包括课前预习的情况、实验过程的操作规范与时间统筹能力、实验习惯、 实验报告等。只要我们的评价机制不会让诚实的人吃亏, 学生就不会冒险去弄虚作假, 长此以往, 诚信将成为人们自觉遵守的行为准则。此外, 在实验过程中往往需要同学间相互帮助和合作, 这有 利于培养学生友善互助的品德。不限于实验课, 无机化学理论课中也有能与合作友善相关联的内容。 比如化学反应中的正催化剂就是友善的最好例证, 它无私地帮助反应物加快反应的步伐, 要是浓度 和温度也一起来助力, 则能进一步提高时效。

\section{4 结语}

以上仅是从几个大的方面说明了无机化学及无机化学实验课在育人中的作用。此外, 这些课程 中还有很多内容可以用于教育学生自律、自省、自强等。而同样的教学内容, 不同的教师也会有不 同的思政教育观点。只要教师用心挖掘课程中的思政资源并贯穿到教学实践中, 就能实现专业课程 与思政课程同心同向的育人格局，有望达成 “立德树人” 的目标，培养出德才兼备的人才。

\section{参 考 文 献}

[1] 展鸠, 蒋小飞, 王艺铭, 兰共德, 刘新泳. 大学化学, 2019, 34 (11), 61.

[2] 马亚鲁, 马骁飞, 田昀, 秦学, 高洪苓, 刘华姬, 鲁凡丽, 王晓东, 王兴尧, 李丹峰, 等. 大学化学, 2020, 35 (8), 48.

[3] 要红昌, 李一珂, 武杰, 李中军. 大学化学, 2020, 35 (8), 54.

[4] 徐玲, 魏恒伟, 魏灵灵, 马艺, 王晓明, 焦桓. 大学化学, 2021, 36 (3), 1912042.

[5] 刘天府. 大学化学, 2020, 35 (8), 44.

[6] 展树中. 大学化学, 2020, 35 (8), 107.

[7] 解从霞, 李光九, 耿延玲, 王小燕. 大学化学, 2019, 34 (11), 38.

[8] 藏云浩, 高峰, 王蓉蓉, 花开慧. 山东化工, 2020, 49 (1), 155,

[9] Miessler, G. L.; Fischer, P. J.; Tarr, D. A. Inorganic Chemistry, 5th ed.; Pearson Education, Inc.: Upper Saddle River, NJ, USA, 2014 ; pp. 364-382.

[10] 张祖德. 无机化学. 第 2 版. 合肥: 中国科学技术大学出版社, 2014: 298-315, 295.

[11] Kean, S. 元素的盛宴. 第 2 版. 杨蓓, 阳㬢, 译. 南宁: 接力出版社, 2015: 135-137, 114-116.

[12] 朱晶, 叶青, 黄艳红. 科技导报, 2014, 32 (10), 15 .

[13] 刘思德. 稀土信息, 2015, No. 5, 10 .

[14] 杨丽, 张小雨, 张文灿. 稀土信息, 2019, No. 9, 34 . 